\title{
Erratum to: Thermotherapy. An alternative for the treatment of American cutaneous leishmaniasis
}

\author{
Liliana López ${ }^{1}$ Martha Robayo², Margarita Vargas² and Iván D. Vélez ${ }^{1 *}$
}

\section{Erratum}

The original publication [1] misses 4 tables and 1 figure which should have been available as additional files. The missing additional files have been included with this erratum as well as a list with description which can be found below.

Table S1: As shown in Additional file 1, both groups had similar demographic, clinical and parasitologic characteristics.

Table S2: By intention-totreat, the definitive healing rate in the thermotherapy group was 58.5\% (95\% IC 49-66) and $72 \%$ (95\% IC 78-92) in the Meglumine antimoniate group, as shown on Additional file 2.

Table S3 and the Leishmania species identified. There was also no association between treatment and other variables such as number, location and lesion type or with the geographical area of Colombia where the infection occurred (Additional file 3).

Table S4: Additional file 4 shows the systemic and local side effects found in this study.

Figure S1: Additional file 5 Flow diagram.

\section{Additional files}

Additional file 1: Table S1. Baseline characteristics of the volunteers. (PDF 198 kb)

Additional file 2: Table S2. Efficacy of meglumine antimoniate and thermotherapy. Analysis by protocol and intention-to-treat. (PDF $174 \mathrm{~kb}$ )

Additional file 3: Table S3. Efficacy of the Meglumine Antimoniate and Thermotherapy stratified by parasite species, anatomic location, number and type of lesions and geographic region of the infection. (PDF $188 \mathrm{~kb}$ )

Additional file 4: Table S4. Incidence and Relative Risk of local and systemic side effects at mid-treatment and at the end of treatment. (PDF 222 kb)

Additional file 5: Figure S1. Diagram of the volunteers who were part of the study. (PDF $89 \mathrm{~kb}$ )

\author{
Author details \\ ${ }^{1}$ Program for the Study and Control of Tropical Disease, University of \\ Antioquia, Carrera 53 \#61-30, Medellín, Colombia. ${ }^{2}$ Dirección de Sanidad, \\ DISAN, Colombia Army, Bogotá, Colombia.
}

Received: 11 July 2017 Accepted: 11 July 2017

Published online: 01 September 2017

\section{Reference}

1. Liliana L. Thermotherapy. An alternative for the treatment of American cutaneous leishmaniasis. Trials. 2012;13:58. doi:10.1186/1745-6215-13-58.

* Correspondence: idvelez@pecet-colombia.org

${ }^{1}$ Program for the Study and Control of Tropical Disease, University of

Antioquia, Carrera 53 \#61-30, Medellín, Colombia

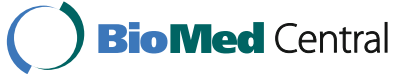

(c) The Author(s). 2017 Open Access This article is distributed under the terms of the Creative Commons Attribution 4.0 International License (http://creativecommons.org/licenses/by/4.0/), which permits unrestricted use, distribution, and reproduction in any medium, provided you give appropriate credit to the original author(s) and the source, provide a link to the Creative Commons license, and indicate if changes were made. The Creative Commons Public Domain Dedication waiver (http://creativecommons.org/publicdomain/zero/1.0/) applies to the data made available in this article, unless otherwise stated. 